\title{
Measurement of in vivo rectal mucosal cytokine and eicosanoid production in ulcerative colitis using filter paper
}

E Carty, M De Brabander, R M Feakins, D S Rampton

\begin{abstract}
Background-Excessive mucosal generation of cytokines and eicosanoids has been reported in vitro in ulcerative colitis (UC) using traumatising biopsy techniques, and in vivo using time consuming rectal dialysis.

Aims-To validate a simple filter paper technique to profile rectal mucosal production of cytokines and eicosanoids in vivo in patients with UC compared with controls.

Patients-Forty one patients with UC (21 with active disease) and 16 controls were studied.

Methods-In vitro, recovery of known concentrations of cytokine or mediator applied to filter papers was measured by ELISA following incubation in buffer. In vivo, patients and controls had filter papers apposed to the rectal mucosa briefly through a rigid sigmoidoscope. Filter papers were then incubated prior to assay by ELISA.

Results-In vitro validation studies showed that the filter paper technique could be used to measure mucosal release

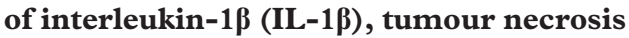
factor $\alpha$ (TNF- $\alpha)$, thromboxane $\mathbf{B}_{2}\left(\mathbf{T X B}_{2}\right)$, and prostaglandin $\mathbf{E}_{2}\left(\mathbf{P G E}_{2}\right)$, but not interferon $\gamma(\mathrm{IFN}-\gamma)$. Mucosal release of IL-1及, TNF- $\alpha$, TXB $_{2}$ and PGE $_{2}$ were significantly increased in active UC $(p=0.001)$ and correlated directly with disease activity $(p=0.02)$.

Conclusions-The filter paper technique confirmed increased rectal mucosal release of cytokines and eicosanoids in UC, in proportion to disease activity. The simplicity, safety and speed of the technique make it a practicable option for use in the outpatient clinic to study the pathogenesis of inflammatory bowel disease, and potentially its response to treatment.

(Gut 2000;46:487-492)
\end{abstract}

Keywords: cytokines; eicosanoids; ulcerative colitis; rectal dialysis

Although the aetiology of inflammatory bowel disease (IBD) remains obscure, its pathogenesis is gradually being unravelled. Numerous studies have indicated the importance of excessive mucosal generation of cytokines (for reviews see Sartor ${ }^{1}$ and Nielsen and Rask-Madsen ${ }^{2}$ ) and inflammatory mediators such as eicosanoids (for reviews see Nielsen and Rask-Madsen, ${ }^{2}$ Rampton and Collins, ${ }^{3}$ and Targan and colleagues ${ }^{4}$ ). Conventional therapy of IBD with corticosteroids and aminosalicylates may act by modulating the profile of cytokines and eicosanoids produced ${ }^{1-4}$ and novel agents are being targeted specifically at excessive production of proinflammatory cytokines (e.g. tumour necrosis factor $\alpha$ $\left.\left(\mathrm{TNF}-\alpha^{5}\right)\right)$ and eicosanoids (e.g. thromboxane ${ }^{6}$ and leukotriene $\mathrm{B}_{4}{ }^{7}$ ).

Existing methods to quantify mucosal generation of cytokines and lipid mediators have several disadvantages. In vitro biopsy methods using tissue obtained by endoscopic biopsy have demonstrated increased levels of prostaglandins, ${ }^{8}$ thromboxane, ${ }^{9}$ leukotrienes, ${ }^{10}$ platelet activating factor, ${ }^{11}$ and proinflammatory cytokines ${ }^{12} 13$ in IBD. However, these methods are traumatising and may be associated with a small risk of bleeding and perforation, particularly in patients with active ulcerative colitis (UC). Furthermore, the trauma of biopsy collection may itself alter the profile of mediators generated by the mucosa.

The most widely used alternative method, in vivo rectal dialysis, has been used to quantify mucosal production of eicosanoids, ${ }^{14}{ }^{15}$ electrolytes, ${ }^{16}$ histamine ${ }^{17}$ and interleukin- $8 .{ }^{18}$ This method is safe for patients, but is a lengthy procedure, taking up to four hours to complete. Additionally, rectal dialysis can be used for detection of only those mediators and cytokines which are small enough to penetrate the dialysis membrane. In some studies the necessity to discard samples showing faecal contamination has been another major disadvantage of this method.

The third major option, rectal perfusion, ${ }^{19}$ is tedious, technically difficult and may itself alter mucosal function.

In 1996, Hendel and colleagues ${ }^{20}$ described a method of assessing mucosal production of interleukin-1 $\beta$ (IL-1 $\beta$ ) and IL-1 receptor antagonist by direct application, via a sigmoidoscope, of a small strip of filter paper to the inflamed rectal mucosa for a period of up to one minute. Specimen collection on filter paper has been used for a variety of body fluids, including blood (e.g. dried blood for phenylketonuria ${ }^{21}$ and cytomegalovirus $\mathrm{DNA}^{22}$

Abbreviations used in this paper: UC, ulcerative colitis; CD, Crohn's disease; IL-1 $\beta$, interleukin- $1 \beta$; IFN- $\gamma$, interferon $\gamma$; TNF- $\alpha$, tumour necrosis factor $\alpha$; $\mathrm{TXB}_{2}$, thromboxane $\mathrm{B}_{2} ; \mathrm{PGE}_{2}$, prostaglandin $\mathrm{E}_{2} ; \mathrm{IBD}$, inflammatory bowel disease; ELISA, enzyme linked immunosorbent assay; CV, coefficient of variation; $\mathrm{IQR}$, interquartile range. 
in neonates) and dental crevicular fluid for eicosanoids. ${ }^{23}$ The potential advantages of the use of filter paper include its simplicity, safety, speed, non-traumatic nature, and low cost.

The aim of this study was to assess the validity of the in vivo filter paper method for quantification of rectal mucosal release of not only IL-1 $\beta^{20}$ but also of interferon $\gamma$ (IFN- $\gamma$ ), TNF- $\alpha$, and the eicosanoids thromboxane $\mathrm{B}_{2}$ $\left(\mathrm{TXB}_{2}\right)$ and prostaglandin $\mathrm{E}_{2}\left(\mathrm{PGE}_{2}\right)$. If adequately validated, the filter paper technique could prove useful for further elucidation in vivo of the pathogenesis of IBD, and for the assessment of both the mode of action of, and response to, conventional and novel therapies.

\section{Methods}

PATIENTS

Twenty one patients with active UC (defined as a mucosal score of 2 or 3 using a standardised sigmoidoscopic score ${ }^{24}$ ) and 20 patients with inactive UC (score 0 or $1^{24}$ ) were studied. Disease activity was assessed clinically using the Powell-Tuck score ${ }^{25}$ and histologically using a semiquantitative score described by Saverymuttu and colleagues. ${ }^{26}$ Sixteen patients undergoing routine sigmoidoscopic assessment because of a change in bowel habit, abdominal pain or rectal bleeding, who were found to have normal rectal mucosa endoscopically and histologically, acted as controls. Details of age, sex, disease extent, and current drug treatments are shown in table 1.

Sample volume restricted the measurement of all mediators in every patient and the lack of clinical requirement for rectal biopsy limited the availability of histology. The number of patients in each group for each result is stated throughout.

All patients gave informed consent and the study was approved by the East London and City Health Authority Research Ethics Committee.

\section{FILTER PAPER PROCEDURE}

Patients were studied during the course of a routine outpatient clinic; no bowel cleansing preparation was used. Through a standard rigid sigmoidoscope, a piece of filter paper (Whatmann No 42, $7 \mathrm{~mm} \times 30 \mathrm{~mm}$ ) was apposed to the rectal mucosa until visibly soaked with luminal secretion (up to 60 seconds). The filter paper was then removed and placed in a vial containing $1 \mathrm{ml}$ of Tris

Table 1 Age, sex, anatomical disease extent, and treatment of patients using the filter paper technique. Disease activity was assessed using sigmoidoscopic score (scores 2 and 3 are active $U C$, scores 0 and 1 are inactive $U C^{24}$ )

\begin{tabular}{llll}
\hline & \multicolumn{2}{l}{ Ulcerative colitis } & \\
\cline { 2 - 3 } & Active & Inactive & Controls \\
\hline $\mathrm{n}$ & 21 & 20 & 16 \\
Age (years) (median (IQR)) & $43(33-53)$ & $51(40-66)$ & $49(36-55)$ \\
Sex (M/F) & $11 / 10$ & $11 / 9$ & $9 / 7$ \\
Disease extent & 14 & 8 & - \\
$\quad$ Distal colitis & 4 & 9 & - \\
$\quad$ Left sided colitis & 3 & 3 & 0 \\
$\quad$ Extensive colitis & 20 & 17 & 0 \\
Treatment & 8 & 4 & 0 \\
$\quad$ Oral or topical 5ASA & 1 & 1 & \\
$\quad$ Oral or topical steroids & & & \\
$\quad$ Azathioprine & & & \\
\hline
\end{tabular}

buffer $0.1 \mathrm{M} \mathrm{pH} 7.4$ in normal saline with human serum albumin $(0.3 \%)$, sodium azide $(0.01 \%)$, and Tween $(0.002 \%)$. The vial was placed on a rocker and agitated gently for 24 hours at $4^{\circ} \mathrm{C}$. Contaminating particles were then removed by centrifugation and the solution stored at $-70^{\circ} \mathrm{C}$ until analysis.

\section{VALIDATION STUDIES}

In vitro recovery of a known concentration of cytokine or eicosanoid was assessed by adding known volumes of standard onto the filter paper, placing the paper in buffer, and incubating for 24 hours, as above. The supernatant was then assayed to measure the concentration recovered.

To assess if rectal luminal bacteria might degrade the cytokine or eicosanoid, in vitro recovery of a known quantity of cytokine or eicosanoid from a filter paper was measured after incubation for 24 hours in buffer containing either $10^{\circ}$ bacteria ( $E$ coli and Streptococcus faecalis) per $1 \mathrm{ml}$ or control buffer containing the same volume of sterile culture broth (Brain heart infusion broth; Oxoid CM25, Basingstoke, UK).

To assess intraindividual variation, two filter papers were apposed to different parts of the rectal mucosa during a single sigmoidoscopy in the same patient for six patients with active UC, six patients with inactive UC and four control patients.

To investigate if a greater volume of fluid, and consequently artefactually more cytokine or lipid mediator, was collected on the filter paper in patients with active UC, the weight of fluid collected for 10 patients with active disease, 12 with inactive disease and eight controls was measured.

\section{RECTAL DIALYSIS}

In vivo rectal dialysis was used as a comparator for the filter paper technique on eight occasions in two patients. A standard method was used. ${ }^{14}$ A $12 \mathrm{~cm}$ long dialysis bag (volume $4 \mathrm{ml}$; Visking seamless cellulose tubing 8/32) filled with an isotonic saline based buffer containing 10\% dextran was gently inserted into the patient's rectum. The bag was withdrawn after two hours and the contents emptied into a test tube and immediately frozen at $-70^{\circ} \mathrm{C}$ until analysis. $\mathrm{TXB}_{2}$ concentration in the fluid was measured by ELISA. The molecular weights of IL-1 $\beta(17.4 \mathrm{kD})$ and TNF- $\alpha(17 \mathrm{kD})$ were too high to allow penetration through the dialysis membrane (molecular weight cut off of the dialysis membrane used was $12-15 \mathrm{kD}$ ): comparison of rectal dialysis and the filter paper technique for the cytokines was therefore not performed.

\section{ASSAYS}

All eicosanoids and cytokines were measured in duplicate on unextracted fluid using commercial enzyme linked immunosorbent assay (ELISA) kits. Serial dilution of selected samples revealed parallelism with the assay standards and standards made up in incubation buffer. $\mathrm{TXB}_{2}$ standards made up in the same dilution of $10 \%$ dextran ( 1 in 5 ) as the 
Table 2 Assay characteristics

\begin{tabular}{|c|c|c|c|c|c|}
\hline Mediator & $\begin{array}{l}\text { ELISA kit } \\
\text { supplier }\end{array}$ & Sensitivity & Cross reactivity & $\begin{array}{l}\text { Intra-assay } \\
C V\end{array}$ & $\begin{array}{l}\text { Interassay } \\
C V\end{array}$ \\
\hline $\mathrm{IL}-1 \beta$ & Medgenix & $2 \mathrm{pg} / \mathrm{ml}^{\star}$ & None ${ }^{\star}$ & $13.5 \%$ & $4.6 \% \star$ \\
\hline IFN- $\gamma$ & Medgenix & $0.03 \mathrm{iu} / \mathrm{ml}^{\star}$ & None ${ }^{\star}$ & $3.5 \%$ & $7.9 \%$ * \\
\hline TNF- $\alpha$ & Medgenix & $3 \mathrm{pg} / \mathrm{ml}^{\star}$ & None* & $8.1 \%$ & $9.9 \%$ * \\
\hline $\mathrm{TXB}_{2}$ & R\&D Systems & $8 \mathrm{pg} / \mathrm{ml}$ & $\begin{array}{l}7.1 \% \text { for } 2,3 \text {, dinor } \mathrm{TXB}_{2}{ }^{\star} \\
<0.01 \% \text { for } \mathrm{PGE}_{2}^{\star}\end{array}$ & $6.8 \%$ & $18 \%$ \\
\hline $\mathrm{PGE}_{2}$ & R\&D Systems & $36 \mathrm{pg} / \mathrm{ml}$ & $\begin{array}{l}70 \% \text { for } \mathrm{PGE}_{1}^{\star} \\
<0.1 \% \text { for } \mathrm{TXB}_{2}^{\star}\end{array}$ & $4.6 \%$ & $24 \%$ \\
\hline
\end{tabular}

${ }^{\star}$ Manufacturer's data. CV, coefficent of variation.

Table 3 In vitro recovery of known amounts of eicosanoids and cytokines from filter papers incubated in buffer alone, buffer containing colonic bacteria, and buffer containing sterile culture broth. Median (IQR) percentage recovery is shown for in vitro recovery from buffer alone; for recovery from buffer containing bacteria or sterile culture broth, mean percentage recovery is shown

\begin{tabular}{lllllll}
\hline Mediator & $\begin{array}{l}\text { Recovery from } \\
\text { buffer (\%) }\end{array}$ & $n$ & $\begin{array}{l}\text { Recovery in the } \\
\text { presence of colonic } \\
\text { bacteria (\%) }\end{array}$ & $\begin{array}{l}\text { Recovery in the } \\
\text { presence of culture } \\
\text { broth (\%) }\end{array}$ & $n$ \\
\hline IL-1 $\beta$ & $84(76-91)$ & 8 & 82 & 2 & 78 & 2 \\
IFN- $\gamma$ & $15(12-18)$ & 6 & Not assessed & 2 & Not assessed & 2 \\
TNF- $\alpha$ & $88(75-106)$ & 6 & 92 & 2 & 125 & 2 \\
TXB $_{2}$ & $99(95-107)$ & 6 & 99 & 2 & 87 & 2 \\
PGE $_{2}$ & $96(92-99)$ & 4 & 110 & 2 & 101 & 2 \\
\hline
\end{tabular}

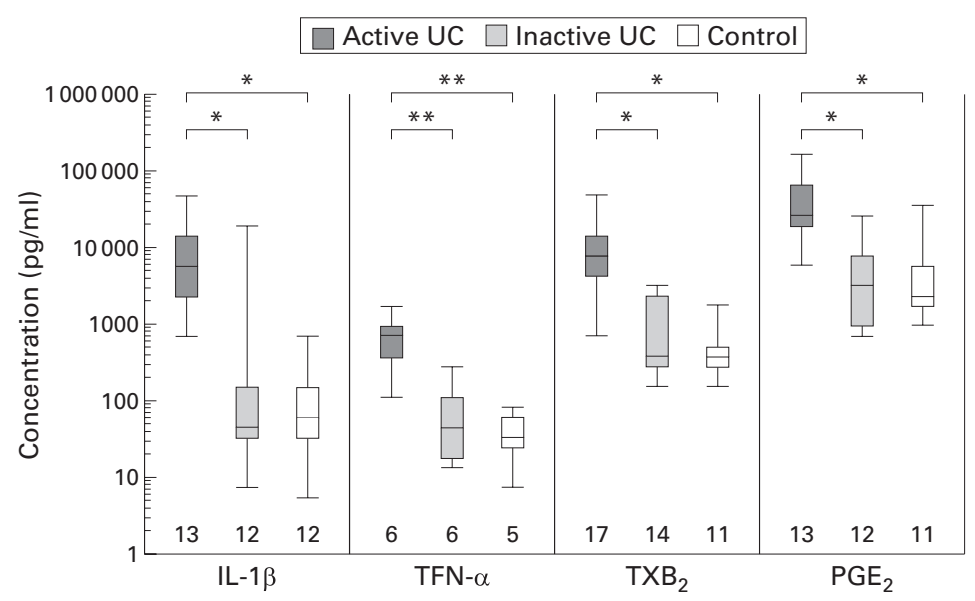

Figure 1 Rectal mucosal release of interleukin $1 \beta$ (IL- $\beta$ ), tumour necrosis factor a $(T N F-a)$, thromboxane $B_{2}\left(T X B_{2}\right)$, and prostaglandin $E_{2}\left(P G E_{2}\right)$, measured by the filter paper technique in active ulcerative colitis (UC), inactive UC (defined by sigmoidoscopic scor $\left.^{24}\right)$ and in controls. Box and whisker plots are shown where the box is the interquartile range, the horizontal line the median, and the whiskers show the highest and lowest values. Numbers of patients studied are shown above the $x$ axis. ${ }^{\star} p<0.0001,{ }^{\star \star} p<0.001$.

Table 4 Correlation coefficients and p values of significance for the relationship between rectal mucosal release of cytokines and eicosanoids measured with the filter paper technique, and sigmoidoscopic, ${ }^{24}$ clinical activity, ${ }^{25}$ and histological ${ }^{26}$ scores in patients with ulcerative colitis

\begin{tabular}{|c|c|c|c|c|}
\hline Score & Mediator & $n$ & $\begin{array}{l}\text { Correlation } \\
\text { coefficient }(r)\end{array}$ & $p$ Value \\
\hline \multicolumn{5}{|c|}{ Sigmoidoscopic score } \\
\hline & IL-1 $\beta$ & 25 & +0.71 & 0.0001 \\
\hline & TNF- $\alpha$ & 12 & +0.76 & 0.005 \\
\hline & $\mathrm{TXB}_{2}$ & 31 & +0.80 & $<0.0001$ \\
\hline & $\mathrm{PGE}_{2}^{2}$ & 25 & +0.75 & $<0.0001$ \\
\hline \multicolumn{5}{|c|}{ Clinical activity score } \\
\hline & IL-1 $\beta$ & 25 & +0.43 & 0.0007 \\
\hline & TNF- $\alpha$ & 12 & +0.89 & 0.02 \\
\hline & $\mathrm{TXB}_{2}$ & 31 & +0.69 & $<0.0001$ \\
\hline \multirow{2}{*}{\multicolumn{5}{|c|}{ Histological score }} \\
\hline & & & & \\
\hline & IL-1 $\beta$ & 17 & +0.76 & 0.04 \\
\hline & TNF- $\alpha$ & 10 & +0.71 & $<0.0001$ \\
\hline & $\mathrm{TXB}_{2}$ & 16 & +0.87 & $<0.0001$ \\
\hline & $\mathrm{PGE}_{2}^{2}$ & 16 & +0.64 & 0.01 \\
\hline
\end{tabular}

rectal dialysis samples also revealed parallelism with standards made up in assay buffer. Details of the commercial companies from which the ELISA kits were obtained, sensitivity, cross reactivity and precision (intra- and interassay coefficients of variation) are shown in table 2 . The intra-assay coefficient of variation was calculated on duplicate measurements of 16 samples (eight highest and eight lowest) using a method described by Bland and Altman. ${ }^{27}$ Similarly, the interassay coefficients of variation for $\mathrm{TXB}_{2}$ and $\mathrm{PGE}_{2}$ were calculated on repeated duplicate measurements from two samples in five assays using the same statistical method. ${ }^{27}$

\section{STATISTICAL METHODS}

Statistical comparisons between groups were made using the Mann-Whitney U test (twotailed). Correlations between two sets of data were assessed by Spearman's rank correlation (two-tailed). The coefficient of variation of paired results was calculated as described by Bland and Altman. ${ }^{27}$ Comparison of the two methods of measurement (filter paper method and rectal dialysis) was performed using a simple correlation rather than a method to test agreement described by Bland and Altman, ${ }^{28}$ as the aim was to investigate if the values obtained using the filter paper technique reflected those of rectal dialysis rather than resembled them in magnitude.

In the in vivo validation studies to assess the influence of the volume of fluid collected by the filter paper, results are expressed as $\mathrm{pg} / \mathrm{mg}$ of mucosal fluid collected; all other results are expressed as concentration ( $\mathrm{pg} / \mathrm{ml}$ of incubation fluid).

\section{Results}

IN VITRO VALIDATION

Data for eicosanoid and cytokine recovery after addition to the filter paper in vitro and incubation for 24 hours in buffer at $4^{\circ} \mathrm{C}$ are shown in table 3. Adequate recoveries were achieved for IL- $1 \beta, \mathrm{TNF}-\alpha$, and the eicosanoids $\mathrm{TXB}_{2}$ and $\mathrm{PGE}_{2}$. However, there was low recovery of IFN- $\gamma$. For IFN- $\gamma$, repeated experiments using a four hour incubation also gave low median (interquartile range (IQR)) recovery of $18 \%$ $(16-38 \%)(n=6)$. The low recovery of IFN- $\gamma$ invalidated further attempts at in vivo study of this cytokine using the filter paper technique.

Recovery of cytokines and lipid mediators after addition to the filter paper in vitro and its incubation for 24 hours in buffer containing bacteria or sterile culture broth is shown in table 3. Colonic bacteria in the buffer did not appear to degrade the cytokines or eicosanoids.

CYTOKINES IN ULCERATIVE COLITIS

The median concentration of IL- $1 \beta$ in filter paper incubation fluid in active UC was 155 -fold that of controls $(\mathrm{p}<0.0001)$ and $277-$ fold that of patients with inactive UC $(p<0.0001)$ (fig 1$)$. The concentration of IL-1 $\beta$ correlated directly with sigmoidoscopic, clinical activity, and histological activity scores (table 4).

The median concentration of TNF- $\alpha$ in filter paper incubation fluid in active UC was 23 times that of controls $(p=0.003)$ and 20 times that of patients with inactive UC $(p=0.001)$ (fig 
Table 5 Weight of fluid collected on the filter paper and the corrected IL-1 $\beta, T N F a$, and eicosanoid levels (for weight) for patients with active and inactive ulcerative colitis(defined by sigmoidoscopic score) and in controls. Median (IQR) are shown

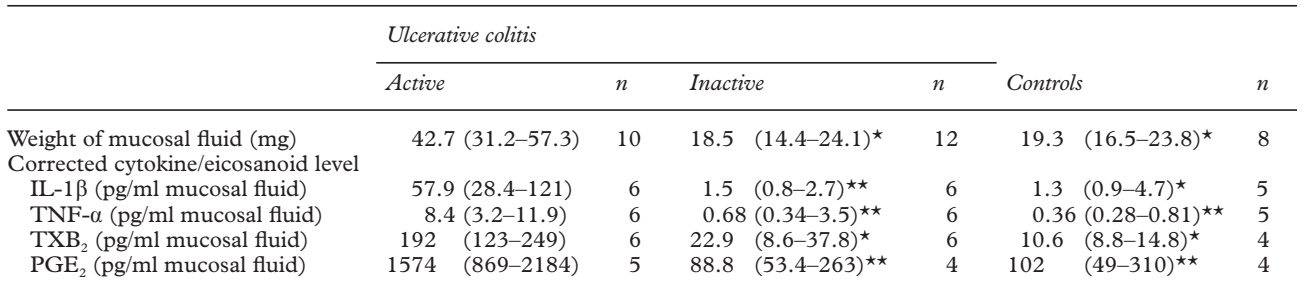

${ }^{\star} \mathrm{p}<0.0001,{ }^{\star \star} \mathrm{p}=0.02$ compared with active UC

1). $\mathrm{TNF}-\alpha$ release showed a positive correlation with sigmoidoscopic, histological, and clinical activity scores (table 4 ).

EICOSANOIDS IN ULCERATIVE COLITIS

Median concentrations of $\mathrm{TXB}_{2}$ and $\mathrm{PGE}_{2}$ in rectal mucosal fluid in active UC were 39 - and 12 -fold those of controls ( $p<0.0001$ for both) and 35 -fold and 10-fold those of patients with inactive UC $(\mathrm{p}<0.0001$ for both) (fig 1). Release of $\mathrm{TXB}_{2}$ and $\mathrm{PGE}_{2}$ correlated directly with sigmoidoscopic, histological, and clinical activity scores (table 4 ).

IN VIVO VALIDATION

The coefficients of variation ${ }^{27}$ for IL- $1 \beta, \mathrm{TXB}_{2}$, and $\mathrm{PGE}_{2}$ concentrations from the paired filter paper samples were $61 \%(n=5), 60 \%(n=6)$, and $43 \%(n=5)$, respectively, in the active disease group, $16 \%(n=5), 30 \%(n=6)$, and $20 \%$ $(n=4)$ in the inactive group, and $30 \%(n=4)$, $72 \%(n=4)$, and $35 \%(n=4)$ in the control group. For TNF- $\alpha$, the coefficient of variation was $5 \%(n=6$, three active patients, one inactive and two controls).

The median weight of fluid collected on the filter papers from patients with active disease was significantly greater than that collected from inactive patients and controls $(\mathrm{p}<0.0001)$ (table 5). There was a significant positive correlation between disease activity measured by sigmoidoscopic score and the weight of mucosal fluid collected $(r=+0.58, \mathrm{p}<0.0001)$. However, when the concentrations of IL-1 $\beta$, TNF- $\alpha, \mathrm{TXB}_{2}$, and $\mathrm{PGE}_{2}$ measured were corrected for the weight of fluid collected, differences in the amounts of cytokine and eicosanoid between the clinical groups remained highly significant with higher amounts of IL- $1 \beta, \mathrm{TNF}-\alpha, \mathrm{TXB}_{2}$, and $\mathrm{PGE}_{2}$ per $\mathrm{mg}$ of mucosal fluid collected in the active group compared with the inactive $(p=0.003, p=0.02$, $\mathrm{p}<0.0001$, and $\mathrm{p}=0.0002$, respectively) and control $(\mathrm{p}<0.0001, \mathrm{p}=0.0021, \mathrm{p}<0.0001$, and $\mathrm{p}=0.0009$, respectively) groups (table 5 ). The percentages of the differences between the samples from patients with active UC and controls that could be explained by increased mucosal fluid weight for IL- $1 \beta, \mathrm{TNF}-\alpha, \mathrm{TXB}_{2}$, and $\mathrm{PGE}_{2}$ were $0.8 \%, 3 \%, 3.8 \%$, and $8.3 \%$.

COMPARISON WITH RECTAL DIALYSIS

In each of two patients with active UC, the filter paper technique was compared with in vivo rectal dialysis ${ }^{14}$ on four occasions over eight days. The filter paper was collected just before the start of a two hour rectal dialysis. For four

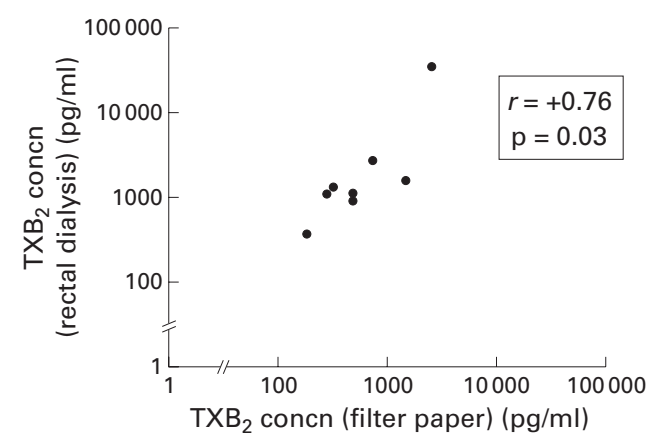

Figure 2 Correlation of measurements of rectal mucosal thromboxane $\left(\mathrm{TXB}_{2}\right)$ release using the filter paper method and rectal dialysis. Two patients with active ulcerative colitis underwent the filter paper technique and two hour rectal dialysis on eight occasions. The $x$ axis shows the values obtained by the filter paper method and the $y$ axis the values obtained by rectal dialysis.

serial measurements of mucosal $\mathrm{TXB}_{2}$ release over eight days with the filter paper technique and rectal dialysis in each patient, there was a positive correlation between the results obtained by the two methods $(r=+0.76, \mathrm{p}=0.03)$ (fig 2).

\section{Discussion}

In this study, we have confirmed the validity of the filter paper method for studying release of IL-1 $\beta$ into rectal mucosal fluid and have extended its application to the measurement of TNF- $\alpha$ and the eicosanoids $\mathrm{TXB}_{2}$ and $\mathrm{PGE}_{2}$.

The results of the in vitro recovery experiments indicated that the use of the filter paper technique in vivo was feasible for IL-1 $\beta$, $\mathrm{TNF}-\alpha, \mathrm{TXB}_{2}$, and $\mathrm{PGE}_{2}$. However, recovery of IFN- $\gamma$ from the filter paper in vitro, regardless of its incubation time, was very low. The inability to elute this cytokine from the filter paper satisfactorily precluded reliable evaluation of rectal mucosal release in vivo using the filter paper method.

The paired in vivo validation experiments showed that there was considerable intraindividual variation for the filter paper method, particularly for those patients with active UC and the control group. The coefficient of variation $(\mathrm{CV})$ of paired filter papers from the same individuals (intraindividual variation) was higher than the reported CV for rectal dialysis $\left(9-37 \%{ }^{14}{ }^{29}\right)$ and biopsy incubation techniques $\left(6-20 \%{ }^{10}{ }^{30}{ }^{31}\right)$. However, the very large difference in the median values for IL- $1 \beta, \mathrm{TNF}-\alpha$, $\mathrm{TXB}_{2}$, and $\mathrm{PGE}_{2}$ release between the active UC and the inactive UC or control groups makes lack of reproducibility of the filter paper method unimportant for most applications. 
The greater weight of mucosal fluid collected on the filter paper of those patients with active UC accounts for a small proportion $(<10 \%)$ of the differences in IL- $1 \beta, \mathrm{TNF}-\alpha, \mathrm{TXB}_{2}$, and $\mathrm{PGE}_{2}$ levels between the patient groups. In practice, however, the advantage of the minor increase in accuracy provided by correcting for the volume of fluid collected on the filter paper is outweighed by the need to weigh it before and after mucosal apposition. Accordingly, apart from table 5, our results are presented uncorrected for the weight of fluid collected on the filter paper.

As the final validation procedure, we showed that the filter paper method gave results for $\mathrm{TXB}_{2}$ which, although lower in magnitude, closely paralleled those obtained by in vivo rectal dialysis, the technique often considered to be the best method for measuring mediator levels in vivo. ${ }^{14} 15$

Excess mucosal production of IL-1 $\beta$ and eicosanoids in active UC, which has previously been demonstrated using other methods, ${ }^{15}$ has been confirmed using this filter paper technique. Mucosal release of IL-1 $\beta$ and eicosanoids correlated well with disease activity, however measured.

Existing data on mucosal production of TNF- $\alpha$ in IBD are contentious. In UC, as in Crohn's disease (CD), there are conflicting reports of TNF- $\alpha$ mRNA levels in mucosal biopsies. Some studies show increased expression in both active ${ }^{32}$ and inactive ${ }^{33}$ disease, while others report no increase in either active $e^{34}$ or inactive ${ }^{35} 36$ UC: the apparent discrepancies between these studies may be explained by methodological differences. Mucosal biopsies from patients with active UC, cultured in vitro, released increased amounts of $\mathrm{TNF}^{-} \alpha$ compared with controls. ${ }^{37}$ Luminal TNF- $\alpha$ concentrations, investigated using colonic perfusion studies in adults ${ }^{38} 39$ and by assay of faeces in children, ${ }^{40}$ were increased in active UC. A recent report suggested that $\mathrm{TNF}-\alpha$ production by cultured lamina propria mononuclear cells in vitro can predict clinical relapse in CD. ${ }^{41}$ Our study is the first to demonstrate increased luminal TNF- $\alpha$ concentrations using a simple, repeatable in vivo method.

For measurement of mucosal release of a mediator, cytokine or other substance by the filter paper technique, it must be shown in in vitro experiments to be adsorbed onto the filter paper, adequately recoverable from the filter paper, stable during incubation with mucosal fluid contaminated incubate, and present at a detectable concentration. These conditions were achieved for IL- $1 \beta, \mathrm{TNF}-\alpha$, $\mathrm{TXB}_{2}$, and $\mathrm{PGE}_{2}$. The advantages of the filter paper over other methods are primarily its safety, ease, and speed; furthermore, it is free from the molecular weight restriction of rectal dialysis. With the filter paper method, the rectal mucosal fluid is directly sampled and thus, unlike rectal dialysis, prolonged insertion of the filter paper for equilibration is not required.

The filter paper method could be applied to any mediator for which the above criteria are met. It could also be used to study mediator release from involved mucosa in other diseases, including infectious colitis and collagenous colitis in which increased eicosanoid release has been shown. ${ }^{152}$ In CD, the filter paper method is likely to be most useful when applied to overtly abnormal mucosa. However, in patients with CD and macroscopically normal rectal mucosa, abnormalities have been reported including, for example, in histology, ${ }^{43} 44$ mucosal thromboxane production, ${ }^{9}$ and vasoactive intestinal peptide content. ${ }^{45}$ This suggests that using the filter paper method in patients with $C D$ without rectal involvement may provide interesting results for some cytokines or mediators.

In summary, this simple, safe, speedy, and inexpensive filter paper method can be used in the outpatient clinic for assessment of rectal mucosal release of a range of cytokines and other mediators. The simplicity and low cost of the method also make it applicable in areas of the world where medical facilities are limited. The technique may prove helpful to investigate further the pathogenesis of UC. It also has the potential to shed new insights into the mode of action and to monitor the effects of current or novel treatments.

We are very grateful to Vera Roels for technical assistance and to Janssen Research Foundation for financial support.

1 Sartor RB. Cytokines in intestinal inflammation: pathophysiological and clinical considerations. Gastroenterology 1994;106:533-9.

2 Nielsen OH, Rask-Madsen J. Mediators of inflammation in chronic inflammatory bowel disease. Scand $\mathcal{F}$ Gastroenterol Suppl 1996;216:149-59.

3 Rampton DS, Hawkey CJ. Prostaglandins and ulcerative colitis. Gut 1984;25:1399-413.

4 Rampton DS, Collins CE. Review article: thromboxanes in inflammatory bowel disease-pathogenic and therapeutic implications. Aliment Pharmacol Ther 1993;7:357-67.

5 Targan SR, Hanauer SB, van Deventer SJ, et al. A short-term study of chimeric monoclonal antibody cA2 to tumor necrosis factor alpha for Crohn's disease. $\mathrm{N} \mathrm{Engl} \mathcal{F}$ Med 1997;337:1029-35.

6 Casellas F, Papo M, Guarner F, et al. Effects of thromboxane synthase inhibition on in vivo release of inflammatory mediators in chronic ulcerative colitis. Eur $\mathcal{F}$ Gastroenterol Hepatol 1995; 7:221-6.

7 Roberts WG, Simon TJ, Berlin RG, et al. Leukotrienes in ulcerative colitis: results of a multicenter trial of a leukotriene biosynthesis inhibitor, MK-591. Gastroenterology 1997;112:725-32.

8 Sharon P, Ligumsky M, Rachmilewitz D. Role of prostaglandins in ulcerative colitis. Enhanced production during active disease and inhibition by sulfasalazine. Gastroenterology 1978;75:638-40

9 Hawkey CJ, Karmeli F, Rachmilewitz D. Imbalance of prostacyclin and thromboxane synthesis in Crohn's disease. Gut 1983;24:881-5.

10 Gertner DJ, Rampton DS, Stevens TR, et al. Verapamil inhibits in-vitro leukotriene B4 release by rectal mucosa in active ulcerative colitis. Aliment Pharmacol Ther 1992;6: 163-8.

11 Rachmilewitz D, Karmeli F, Eliakim R. Platelet-activating factor-a possible mediator in the pathogenesis of ulcerative colitis. Scand f Gastroenterol Suppl 1990;172:19-21.

12 Ligumsky M, Simon PL, Karmeli F, et al. Role of interleukin 1 in inflammatory bowel disease-enhanced production 1 in inflammatory bowel disease-enhance

13 Daig R, Andus T, Aschenbrenner E, et al. Increased interleukin 8 expression in the colon mucosa of patients with inflammatory bowel disease. Gut 1996;38:216-22.

14 Rampton DS, Sladen GE, Youlten LJ. Rectal mucosal prostaglandin E2 release and its relation to disease activity, electrical potential difference, and treatment in ulcerative colitis. Gut 1980;21:591-6.

15 Lauritsen K, Laursen LS, Bukhave K, et al. In vivo profiles of eicosanoids in ulcerative colitis, Crohn's colitis, and Clostridium difficile colitis. Gastroenterology 1988;95:11-7.

16 Sandle GI, Hayslett JP, Binder HJ. Effect of glucocorticoids on rectal transport in normal subjects and patients with ulcerative colitis. Gut 1986;27:309-16.

17 Rampton DS, Murdoch RD, Sladen GE. Rectal mucosal histamine release in ulcerative colitis. Clin Sci 1980;59: 389-91.

18 Casellas F, Borruel N, Papo M, et al. Antiinflammatory effects of enterically coated amoxicillin-clavulanic acid in active ulcerative colitis. Inflamm Bowel Dis 1998;4:1-5. 
19 Raab Y, Hallgren R, Knutson L, et al. A technique for segmental rectal and colonic perfusion in humans. $A m \mathscr{f}$ Gegmental rectal and colonic

20 Hendel J, Nielsen OH, Madsen S, et al. A simple filter-paper technique allows detection of mucosal cytokine levels in vivo in ulcerative colitis. Interleukin-1 and interleukin-1receptor antagonist. Dig Dis Sci 1996;41:1775-9.

21 Reilly AA, Bellisario R, Pass KA. Multivariate discrimination for phenylketonuria (PKU) and non-PKU hyperphenylalaninemia after analysis of newborns' dried blood-spot specimens for six amino acids by ion-exchange chromatography. Clin Chem 1998;44:317-26.

22 Shibata M, Takano H, Hironaka T, et al. Detection of human cytomegalovirus DNA in dried newborn blood filter paper. F Virol Methods 1994;46:279-85.

23 Offenbacher S, Farr DH, Goodson JM. Measurement of prostaglandin $\mathrm{E}$ in crevicular fluid. $\mathcal{F}$ Clin Periodontol 1981; 8:359-67.

24 Baron J, Connell A, Lennard-Jones A. Variation between observers in describing mucosal changes in proctocolitis. BMF 1964;1:89-92.

25 Powell-Tuck J, Day DW, Buckell NA, et al. Correlations between defined sigmoidoscopic appearances and other measures of disease activity in ulcerative colitis. Dig Dis Sci 1982;27:533-7.

26 Saverymuttu SH, Camilleri $\mathrm{M}$, Rees $\mathrm{H}$, et al. Indium 111-granulocyte scanning in the assessment of disease extent and disease activity in inflammatory bowel disease. A comparison with colonoscopy, histology, and fecal indium 111-granulocyte excretion. Gastroenterology 1986; 90:1121-8.

27 Bland M. Clinical measurement-repeatability and precision in measurement. In: Bland M, ed. An introduction to medical statistics, 3rd ed. Oxford: Oxford University Press, 1991: 276-8.

28 Bland JM, Altman DG. Statistical methods for assessing agreement between two methods of clinical measurement. Lancet 1986;i:307-10

29 Casellas F, Borruel N, Papo M, et al. Usefulness of rectal dialysis to determine intrarectal eicosanoid release in dialysis to determine intrarectal eicosanoid release
ulcerative colitis. Rev Esp Enferm Dig 1997;89:280-8.

30 Collins CE, Benson MJ, Burnham WR, et al. Picotamide inhibition of excess in vitro thromboxane $\mathrm{B} 2$ release by colorectal mucosa in inflammatory bowel disease. Alimen Pharmacol Ther 1996;10:315-20.

31 Mahida YR, Lamming CE, Gallagher A, et al. 5-Aminosalicylic acid is a potent inhibitor of interleukin 1 beta production in organ culture of colonic biopsy specimens from patients with inflammatory bowel disease. Gut 1991;32:50-4.
32 Cappello M, Keshav S, Prince C, et al. Detection of mRNAs for macrophage products in inflammatory bowel disease by in situ hybridisation. Gut 1992;33:1214-19.

33 Masuda H, Iwai S, Tanaka T, et al. Expression of IL-8, TNF-alpha and IFN-gamma m-RNA in ulcerative colitis, particularly in patients with inactive phase. F Clin Lab Immunol 1995;46:111-23.

34 Dionne S, Hiscott J, D'Agata I, et al. Quantitative PCR analysis of TNF-alpha and IL-1 beta mRNA levels in pediatric IBD mucosal biopsies. Dig Dis Sci 1997;42:1557-66.

35 Stevens C, Walz G, Singaram C, et al. Tumor necrosis factor-alpha, interleukin-1 beta, and interleukin- 6 expression in inflammatory bowel disease. Dig Dis Sci 1992;37: $818-26$

36 Isaacs KL, Sartor RB, Haskill S. Cytokine messenger RNA profiles in inflammatory bowel disease mucosa detected by polymerase chain reaction amplification. Gastroenterology 1992;103:1587-95.

37 Sakai T, Kusugami K, Nishimura H, et al. Interleukin 15 activity in the rectal mucosa of inflammatory bowel disease. Gastroenterology 1998;114:1237-43.

38 Raab Y, Gerdin B, Ahlstedt S, et al. Neutrophil mucosal involvement is accompanied by enhanced local production of interleukin-8 in ulcerative colitis. Gut 1993;34:1203-6.

39 Casellas F, Papo M, Guarner F, et al. Intraluminal colonic release of immunoreactive tumour necrosis factor in chronic ulcerative colitis. Clin Sci 1994;87:453-8.

40 Braegger CP, Nicholls S, Murch SH, et al. Tumour necrosis factor alpha in stool as a marker of intestinal inflammation. Lancet 1992;339:89-91.

41 Schreiber S, Nikolaus S, Hampe J, et al. Tumour necrosis factor $\alpha$ and interleukin $1 \beta$ in relapse of Crohn's disease. Lancet 1999;353:459-61.

42 Rask-Madsen J, Grove O, Hansen MG, et al. Colonic transport of water and electrolytes in a patient with secretory diarrhea due to collagenous colitis. Dig Dis Sci 1983;28: $1141-6$

43 Goodman MJ, Skinner JM, Truelove SC. Abnormalities in the apparently normal bowel mucosa in Crohn's disease. Lancet 1976;1:275-8.

44 Korelitz BI, Sommers SC. Rectal biopsy in patients with Crohn's disease. Normal mucosa on sigmoidoscopic examination. $\mathcal{F A M A}$ 1977;237:2742-4.

45 O'Morain C, Bishop AE, McGregor GP, et al. Vasoactive intestinal peptide concentrations and immunocytochemical studies in rectal biopsies from patients with inflammatory bowel disease. Gut 1984;25:57-61. 